\title{
Review \\ Breast cancer, stem cells and prospects for therapy
} Magnus D Lynch, Massimiliano Cariati and Anand D Purushotham

King's College/Guy's St Thomas NHS Foundation Trust, London, UK

Corresponding author: AD Purushotham, amy.byrtus@kcl.ac.uk

Published: 3 July 2006

This article is online at http://breast-cancer-research.com/content/8/3/211 (c) 2006 BioMed Central Ltd
Breast Cancer Research 2006, 8:211 (doi:10.1186/bcr1513)

\section{Stem cells in normal mammary epithelium}

We define a stem cell as an undifferentiated cell for which the mitotic progeny have the potential to generate differentiated cells throughout the lifespan. Implicit in this definition is that stem cells have the capacity for self-renewal. A multipotent stem cell or progenitor gives rise to more than one differentiated cell type; a pluripotent stem cell forms all of the differentiated cell types present in a particular tissue. Although pluripotency is not formally required for the definition of a stem cell, studies of the haematopoietic system and other stem cell compartments have revealed that the most primitive stem cells have the greatest developmental potential.

The mature lactating mammary gland comprises mesenchymal and epithelial elements. The epithelial cells form a branching network of ducts terminating in lobules, which are in turn composed of alveoli. The inner luminal epithelial cells of the ducts and lobules are ensheathed by a basal layer consisting predominantly of contractile myoepithelial cells. All epithelial elements are embedded in a fibrofatty connective tissue matrix [9]. In the human it is from these epithelial elements that the vast majority of mammary tumours arise, and therefore it is with the epithelial lineages that we are primarily concerned. It is noted, however, that epithelialstromal interactions are essential for mammary morphogenesis and development $[10,11]$. Moreover, as discussed in the following, there is increasing evidence that stromal alterations are integral to the evolution of breast cancer.

In contrast to most mammalian organs, breast development is not complete in the neonate, consisting only of a limited network of ducts. At puberty there is extensive ductal proliferation and branching; during pregnancy there is formation of lobuloalveolar units that regress at the termination of lactation [9]. There is therefore generation of new ductal, lobular and basal/myoepithelial cells in adult life.

$\mathrm{ABC}=\mathrm{ATP}$-binding cassette; $\mathrm{AML}=$ acute myeloid leukaemia; $\mathrm{LRC}=$ label retaining cells; $\mathrm{MMTV}=$ mouse mammary tumour virus; $\mathrm{MRU}=$ mammary repopulating unit; $\mathrm{PCR}=$ polymerase chain reaction; $\mathrm{SP}=$ side population. 
Although these new cells could in principle be produced by simple division of differentiated cells, the experimental evidence supports a hierarchical organisation that parallels other epithelial stem cell compartments $[3,4]$ - with a small proportion of multipotent mammary epithelial stem cells that give rise to progressively more committed progenitors, and ultimately to all three mammary epithelial cell types.

\section{Murine mammary epithelial stem cells}

The first evidence in support of a pluripotent mammary epithelial stem cell can be found in the classic transplantation experiments of DeOme and colleagues [12]. It was shown in the mouse that transplantation of small fragments from any portion of the mammary epithelial tree to a cleared mammary fat pad regenerates an entire branching mammary epithelial tree. Furthermore, a fragment can be taken from this regenerated gland and be serially transplanted to another cleared mammary fat pad [13]. Formal proof for the existence of a pluripotent stem cell as opposed to multiple developmentally committed progenitors was not available, however, until a similar experiment was performed with retrovirally tagged cells. Neonatal mice were infected with mouse mammary tumour virus (MMTV), a retrovirus, and randomly chosen fragments of the gland were transplanted from multiparous adult animals to the cleared mammary fat pad of noninfected recipients. Since MMTV integrates at random into the nuclear genome, clones derived from individual infected mammary epithelial cells could be distinguished. It was seen that an entire mammary epithelial tree could be derived from the progeny of a single MMTV-infected cell [14].

Limiting dilution transplantation experiments also support the existence of pluripotent epithelial stem cells in the mouse mammary gland. In these experiments small numbers of dissociated mammary epithelial cells are transplanted so that only a minority of fat pads have epithelial outgrowths, with most of these outgrowths derived from a single mammary epithelial cell. Three types of outgrowths can be distinguished. The first generates a limited network of ducts without lobules, and another type produces a limited outgrowth of lobules without branching ducts. The final outgrowth type has both ductal and lobular development and completely fills the mammary fat pad $[15,16]$. Retroviral labelling confirms that each of these outgrowths is clonal [14].

\section{Cell surface markers}

The dramatic progress made in understanding the haematopoietic system in recent years has come about largely as a consequence of the ability to prospectively identify haematopoietic stem cells on the basis of cell surface antigens [17] and as a consequence of the existence of a robust and well-characterised repopulation assay in the form of bone marrow transplantation. An analogous repopulation assay in combination with limiting dilution transplantation has recently been employed to characterise cells 'mammary repopulating units' (MRUs) within dissociated murine mammary epithelium that can repopulate a cleared mammary fat pad with all mammary epithelial lineages $[18,19]$.

Following removal of cells of nonepithelial lineages, MRUs could be prospectively purified from mammary epithelial cells on the basis of expression of either CD24+CD29hi [19] or

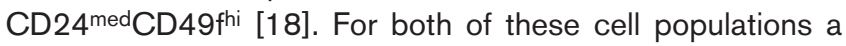
single cell could give rise to epithelial outgrowths in cleared mammary fat pads that contained all mammary epithelial lineages, thereby demonstrating pluripotency. Serial transplantation of cells harvested from these clonal outgrowths to secondary recipients proved the ability of these cells to selfrenew. Sleeman and colleagues independently found MRUs to be enriched in the CD24lo population as opposed to CD24 ${ }^{\text {hi }}$ and CD24- populations [20]. These studies represent not only the first reports of prospective identification of mammary epithelial stem cells, but indeed of any mammalian epithelial stem cells.

It is necessary to reinterpret preceding studies in the light of these new results. It has been previously reported that all cells with the capacity to repopulate the cleared mammary fat pad express sca-1, a haematopoietic stem cell marker [21]. This finding is not supported by the studies of Shackleton, Stingl and colleagues; specifically, CD24+CD29hi cells are not enriched in sca-1+-expressing cells [19] and no MRUs were detected in the sca- $1^{\text {hi }}$ subset of CD29f ${ }^{+}$cells [18]. This discrepancy may be accounted for by the observation of Stingl and colleagues that in-vitro culture per se is sufficient to induce sca-1 in cultured cells. A further significant finding of Stingl and colleagues' study is that mammary epithelial cells that formed colonies in vitro (mammary colony-forming cells) expressed an entirely distinct set of cell surface antigens compared with MRUs. They were also many times more numerous and could be derived from MRUs, implying that mammary colony-forming cells are a separate population of committed progenitors. This has important implications for studies seeking to define a phenotype for human mammary epithelial stem cells on the basis of in-vitro culture [22-24].

Characterisation of prospectively purified MRUs offers insights into their phenotype. Differential staining of mammary epithelial cells for CD24 separates the different mammary cell populations with a high degree of purity. Cytokeratin expression and quantitative PCR reveal that CD24-, CD24lo and CD24hi populations correspond to nonepithelial cells, basal/myoepithelial cells and luminal epithelial cells, respectively [20]. In limited dilution transplantation to the cleared mammary fat pad, CD24 ${ }^{\text {lo }}$ cells had the highest concentration of MRUs and the greatest outgrowth potential. In contrast, CD24 ${ }^{\text {hi }}$ cells had a much lower content of MRUs and were unable to repopulate the entire fat pad, suggesting that mammary epithelial stem cells have the basal/ myoepithelial phenotype [20]. Consistent with this interpretation, flow cytometry reveals that a large proportion of stem cell candidates with the CD24+CD29hi phenotype 
express the basal marker cytokeratin 14 [19]. Oligonucleotide array studies and quantitative PCR similarly found higher levels of cytokeratin 14 and other basal/myoepithelial markers in the CD24 ${ }^{\text {med }}$ CD49fhi population. Further examination of the CD24 ${ }^{\text {med }}$ CD49fhi population at the single cell level, however, revealed that while a proportion of cells expressed basal/ myoepithelial-specific markers and others expressed luminalspecific markers, these were never coexpressed at the single cell level; moreover, approximately one-half of these cells did not express markers of either lineage [18].

In the interpretation of these seemingly contradictory findings it is essential to remember that the frequency of MRUs in the CD24+CD29hi and CD24 ${ }^{\text {med }}$ CD49fhi populations is estimated at $1 / 64$ and $1 / 60$, respectively. Even allowing for loss of MRUs during the purification and transplantation steps, therefore, a large majority of the cells within these populations are transit amplifying cells rather than stem cells. Furthermore, although the prospectively isolated CD24 ${ }^{\mathrm{lo}}$, CD24+CD29hi and CD24 ${ }^{\text {med CD } 49 f h i ~ p o p u l a t i o n s ~ o v e r l a p, ~ i n ~}$ that they contain MRUs, it is unlikely that the identity of the (majority) nonstem cells in these populations corresponds exactly. Until more highly purified and better characterised populations are available, therefore, we must employ great caution when inferring the properties of mammary epithelial stem cells from prospectively isolated populations.

Flow cytometric comparison of the DNA and RNA content in

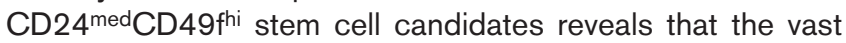
majority of these cells are actively cycling. Despite the earlier caveat that only a small proportion of these cells are actually stem cells, this would not be an unexpected finding since double-labelling experiments (see later) have shown that a large proportion of intestinal epithelial label-retaining cells (LRC) [25] and mammary epithelial LRC [26], which are believed to correspond to stem cells, are actively cycling. Moreover, the c-kitbrightThy $1.1^{\text {loS }}$ ca- $1.1^{+}$Lineage $^{-}$subset of murine bone marrow cells, which is highly enriched in haematopoietic stem cells, regularly traverses the cell cycle [27].

\section{Label-retaining cells}

Within stem cell compartments a small fraction of cells retain the nucleotide label for a large proportion of the lifespan $[28,29]$, and these LRC are widely believed to be stem cells. Retention of the label could simply reflect exceedingly slow turnover; however, recent 'double-labelling' experiments with intestinal epithelium [25] and mammary epithelium [26], in which long-term LRC are pulsed with a second nucleotide label, support Cairns' hypothesis [30] of asymmetrical DNA strand segregation with persistence of an 'immortal strand' in the stem cell and segregation of newly synthesised DNA to daughter cells.

LRC can be identified in the murine mammary gland following labelling during the period of ductal morphogenesis in the neonate $[21,31,32]$. Consistent with their proposed identity as mammary epithelial stem cells, LRC were enriched in the CD24 ${ }^{+}$CD29hi population [19]. Only a small proportion of LRC express keratin 14 or keratin 18, markers of epithelial differentiation [21]. LRC have also been identified in histologically normal human breast tissue implanted in immunodeficient mice [33]; however, in that study the interval between labelling and biopsy was only 2 weeks, so it is unlikely that these cells are highly enriched in mammary epithelial stem cells.

\section{Side population}

The ability to exclude fluorescent dyes such as Hoescht 33342 from the cytoplasm has been employed to isolate a 'side population' (SP) of haematopoietic cells that is highly enriched in haematopoietic stem cells [34]. An analogous population has been identified in primary cultured murine mammary epithelial cells [21] and in uncultured human mammary epithelial cells $[24,33,35]$ and murine mammary epithelial cells [35]. Fluorescent dye exclusion results from the expression of ATP-binding cassette (ABC) family transporter proteins. In cultured human mammary epithelial cells, Abcg2 is thought to be responsible for the SP [24]; studies with triple knockout mice have also implicated Abc1a/1b (Mdr1a/1b) [36]. Unfortunately Abcg2 is universally expressed at high levels in the luminal epithelium of lactating murine and human mammary glands [37], although this does not, in principle, preclude its use as a stem cell marker in the virgin mammary gland.

It has been proposed that the SP is enriched in mammary epithelial stem cells. In support of this hypothesis, murine SP cells give rise to all three mammary epithelial cell lineages when transplanted to cleared mammary fat pads [21,35]; moreover, human SP cells form much larger branching colonies in matrigel than do non-SP cells [33]. SP cells are also highly enriched for mammosphere formation [38]. On the other hand, possibly as a consequence of Hoescht dye toxicity, it has never been demonstrated that the SP is enriched in cells with the capacity to repopulate the cleared mammary epithelial fat pad, and only a small proportion (less than $10 \%$ ) of cells with the capacity to repopulate the cleared mammary fat pad are contained within the SP [18]. LRC also constitute only a small proportion of SP cells [21], and so the jury remains out regarding the precise relationship of SP cells to mammary epithelial stem cells.

\section{Other stem cell markers}

A variety of other markers for mammary epithelial stem cells have been proposed, including $\mathrm{p} 21^{\mathrm{CIP} 1}$, a cyclin-dependent kinase inhibitor, and Msi1, a homologue of the Drosophila Mushashi protein [33]. Since these are not cell surface antigens, however, they cannot be validated in mammary fat pad repopulation assays. A further strategy is Cre recombinase-induced LacZ expression under control of the whey acidic protein promotor $[39,40]$. Mammary epithelial cells activate the whey acidic protein promotor during pregnancy, 
leading to recombination at LoxP sites that results in expression of an intact LacZ transgene in these cells and their mitotic descendents. Following transplantation to a cleared mammary fat pad these 'parity-induced mammary epithelial cells' are pluripotent, giving rise to all three mammary epithelial cell types in addition to duct-limited and lobule-limited outgrowths, although the presence of additional LacZ- $^{-}$cells is required for the formation of intact ductallobular structures. Serial transplantation proved the capacity for self-renewal.

\section{Human mammary epithelial stem cells}

It intuitively seems probable that the human mammary epithelium will be organised along similar lines to that of the mouse, and recent reports support this premise. Clonal patches of X-inactivation [41] and loss of heterozygosity [42] affect large, contiguous regions of breast epithelium, and this has been interpreted as reflecting origin from a common pluripotent stem cell - although the alternative possibility that these alterations arise during development $[43,44]$ cannot be formally excluded. In-vitro culture of dissociated human mammary epithelial cells yields a bipotent myoepithelial/ luminal progenitor and progenitors restricted to basal/myoepithelial and luminal lineages. These different progenitors can be prospectively purified according to expression of a range of cell surface antigens, including MUC-1, the common acute lymphoblastic leukaemia antigen, epithelial cell adhesion molecule and $\alpha_{6}$-integrin [22-24]. In-vitro culture failed to identify a pluripotent progenitor capable of forming ductal cells in addition to luminal cells and basal/ myoepithelial cells. Furthermore, recent reports indicate that the population of murine mammary epithelial cells initiating colony formation in vitro is distinct from the population that repopulates the cleared mammary fat pad [18]. This strongly suggests that these in-vitro studies are characterising committed progenitors rather than pluripotent stem cells.

\section{Mammospheres}

A human papillomavirus E6/E7-immortalised human mammary epithelial cell line has been reported that can form all three mammary epithelial lineages in vitro, although normal function of these cells was not proven [45]. Inspired by techniques developed for the culture of neural stem cells [46], single cell suspensions of human mammary epithelial cells were more recently cultured at limiting dilution in conditions that prevent adherence to the substratum [38]. This technique appears to limit culture-induced differentiation. Under these conditions most of the cells die by apoptosis, but a small proportion survives as floating spherical colony 'mammospheres'. To assess their developmental potential, these mammospheres were dissociated into single cells that were cultured at limiting dilution.

Similar to previous studies unipotent and bipotent progenitors were isolated, but also a subset of progenitors that formed all three mammary epithelial cell types was seen.
In addition, a small proportion of mammosphere-derived cells ( 2-4/1000) formed intact ductal-alveolar structures in three-dimensional matrigel culture. Self-renewal was demonstrated by dissociation of mammospheres, reculture and then reaggregation; cells from the secondary mammospheres and beyond were almost exclusive bipotent or tripotent [38]. It is unclear why the ability to form mammospheres should select for primitive progenitors and stem cells.

\section{Steroid receptor expression}

The extent of lifetime oestrogen exposure is a major risk factor for the development of breast cancer; moreover, approximately two-thirds of human breast cancers express the oestrogen receptor, and the oestrogen receptor status of a patient is highly predictive of response to antioestrogen therapy [47]. It is therefore important to define the relationship between mammary epithelial stem cells and oestrogen receptor expression.

In the human mammary epithelium, $10-20 \%$ of cells are oestrogen receptor-positive. The progesterone receptor is almost invariably co-expressed and these cells are said to be steroid receptor-positive. These cells are located exclusively within the luminal epithelium $[48,49]$, between basal myoepithelial cells and apical luminal cells [33]. Interestingly, a population of undifferentiated small light cells that are candidates for murine epithelial stem cells has previously been described in this position [16,50]. Steroid receptorpositive cells were never dividing, although they were often located adjacent to a dividing cell $[48,49]$, suggesting that they occupy a relatively high position in the differentiation hierarchy.

In an attempt to further define the relationship between steroid receptor expression and mammary epithelial stem cells, steroid receptor expression was investigated in murine mammary epithelial LRC. Although a significant proportion of LRC expressed steroid receptors soon after administration of the label, at later time periods, when LRC are more highly enriched in stem cells, only a very small proportion expressed steroid receptors $[21,26]$. These results suggest that most steroid receptor-positive cells are not mammary epithelial stem cells, but instead are slowly cycling transit amplifying cells near the top of the differentiation hierarchy.

Clarke and colleagues also looked at steroid receptor expression in human mammary epithelial cells transplanted to immunodeficient mice [33]. Fourteen per cent of LRC and a large proportion of cells expressing other candidate stem cell markers were found to be steroid receptor-positive. The chase period was only 2 weeks in this study, however, so it is unlikely that the LRC are highly enriched in mammary epithelial stem cells. Furthermore, the markers investigated (Msi1, p21 CIP1, cytokeratin 19) have never been validated in repopulation assays. 
So, in summary, the emerging picture is that the three mammary epithelial lineages are ultimately derived from a pluripotent self-renewing mammary epithelial stem cell that gives rise to bilineage-restricted and lineage-restricted progenitors with limited proliferative potential.

\section{Breast cancer stem cells}

With analogy to the previous definition of tissue stem cells we can define cancer stem cells as cells that can give rise to all cell types within the tumour and that have the capacity for self-renewal. Since it has not been proven that cancer stem cells are derived directly from tissue stem cells, this is not a requirement of our definition. It has been recognised for some time that only a small minority of the cells within haematopoietic malignancies have the capacity for extensive proliferation, but the possibility that all tumour cells are equivalent and that extensive proliferation is merely a stochastic phenomenon could not be excluded [6]. In 1997, however, Bonnet and Dick showed that the subset of acute myeloid leukaemia (AML) cells capable of transferring the tumour to immunodeficient mice can be prospectively identified according to expression of certain cell surface markers [51]. This proved that heterogeneity is intrinsic to tumour cells, and provided strong support for the cancer stem cell hypothesis. Similar results have since been reported for other haematopoietic malignancies [5] and neural malignancies [8].

As already described, a number of powerful experimental methodologies have been developed to characterise epithelial stem cells. These include the expression of cell surface or intracellular markers, mammosphere formation, exclusion of fluorescent dye by a SP and the retention of the radionucleotide label. It is reasonable to suppose that breast cancer stem cells will share some of the characteristics of normal mammary epithelial stem cells and, with the exception of label retention, all of these approaches have also been employed in efforts to identify breast cancer stem cells within tumours.

\section{Cell surface markers}

The gold standard for proving the existence of a subpopulation of tumourigenic stem cells is the demonstration that a minority of prospectively identified cells is able to transfer the tumour and recapitulate the phenotypic heterogeneity present within the parental tumour, whereas a much larger number of tumour cells lacking the relevant marker(s) cannot. This same subpopulation should again fulfil these criteria when re-isolated from a secondary tumour. This is feasible for haematopoietic malignancies since haematopoietic cells survive well in suspension and therefore tolerate the process of sorting and bone marrow transplantation well. Unfortunately for solid tumours in general, and for breast cancer in particular, the efficiency of tumour initiation in immunodeficient mice from primary dissociated tumour cells is very low. This most probably reflects anoikis in the absence of binding to a substratum in combination with the trauma of dissociation and cell sorting.
Two strategies have been successfully employed to circumvent these limitations and to identify tumourigenic cells within breast cancers. Al-Hajj and colleagues initiated tumours in immunodeficient mice with cells derived from eight human breast-cancer-associated malignant pleural effusions [7]. These cells have already survived selection in vivo for the ability to survive in suspension and to tolerate low oxygen tensions, and this may account for their tolerance to cell sorting. Although one tumour was established directly from a primary breast cancer, cell sorting was only performed following passage in an immunodeficient mouse. It was found that a small proportion of tumourigenic cells could be isolated from dissociated tumour cells by flow cytometry. Following removal of nonepithelial cells, cells with the $\mathrm{CD}_{4} 4^{+} \mathrm{CD} 24^{-/ /} \mathrm{Lin}^{-}$phenotype were 10 -fold to 50 -fold enriched in their ability to initiate tumours compared with unsorted cells. For three of the malignant pleural effusions, further enrichment was possible according to expression of the ESA (epithelial cell adhesion molecule) antigen. As few as $200 \mathrm{CD}^{2} 4^{+} \mathrm{CD} 24^{-/ / 0} \mathrm{ESA}^{+} \mathrm{Lin}^{-}$cells consistently initiated tumours, whereas 10,000 unsorted cells did so only rarely. CD $44^{+} \mathrm{CD} 24^{-/ /}$Lin $^{-}$cells isolated from tumours that had been initiated by these cells were able to transfer the tumour to secondary and subsequent hosts, demonstrating the capacity for self-renewal.

The formation of mammospheres from normal mammary epithelial cells has already been described. Ponti and colleagues employed a similar approach to derive mammospheres from human breast cancers [52]. Mammosphere cells were undifferentiated but, interestingly, a large majority had the same $\mathrm{CD} 44^{+} \mathrm{CD} 24^{-}$phenotype reported by $\mathrm{Al}-\mathrm{Hajj}$ and colleagues. When transferred to differentiating culture conditions, mammospheres produced cells of both luminal and basal/myoepithelial lineages. Mammospheres initiated tumours in the cleared mammary fat pad of immunodeficient mice at 1000-fold greater dilutions than established breast-cancer-derived cell lines. Following enzymatic dissociation, $10-20 \%$ of cells from primary tumour-derived mammospheres formed secondary mammospheres and several cultures were serially expanded for more than 40 passages, proving a capacity for long-term selfrenewal. Mammospheres from more aggressive tumours formed a larger number of secondary mammospheres, suggesting a greater capacity for self-renewal.

Do CD44+/CD24- cells represent breast cancer stem cells? The results of both $\mathrm{Al}-\mathrm{Hajj}$ and colleagues and Ponti and colleagues suggest that breast cancer cells with the capability for long-term self-renewal are enriched within the CD 44+CD24- subset. We should not, however, infer from this that the $\mathrm{CD} 44^{+} \mathrm{CD} 24^{-}$subset of tumour cells is a homogeneous population of cancer stem cells; instead, analogous to prospectively purified mammary epithelial stem cells, this population most probably represents a heterogeneous mix of cancer stem cells and early progenitor cells. 
This is supported by the observation that, for certain of AlHajj and colleagues' malignant pleural effusions, an ESA ${ }^{+}$ subpopulation of CD44+CD24- cells is more highly enriched in tumourigenic cells [7]. Additionally, although virtually all of the cells in Ponti and colleagues' mammospheres were CD $44^{+}{ }^{+}$D24-, only $10-20 \%$ had the capacity for selfrenewal.

Both of these earlier studies, by necessity, impose an intervening selection step between primary cancer cells and cell sorting - the ability to survive in a pleural effusion in the case of Al-Hajj and colleagues' experiments, and the ability to survive in nonadherent culture conditions for Ponti and colleagues' study. It therefore remains formally possible that only the subset of breast cancer stem cells that fulfil these criteria is identified in these studies.

\section{Side population}

A Hoescht dye-effluxing SP has been identified in AML patients that is highly enriched in the ability to transfer the disease to immunodeficient mice [53]. This cell population is believed to contain a high proportion of leukaemia stem cells. A similar SP has been identified in primary neuroblastoma cells and cultured cell lines [54] and in certain established breast-cancer-derived cell lines [54,55]. For a variety of cultured cell lines it was shown that the SP was enriched in cells with the ability to initiate tumours in immunodeficient mice [55], although these studies are somewhat confounded by the higher concentration of (toxic) Hoescht dye present in non-SP cells. Future experimental strategies may include the characterisation of SP cells from primary breast cancers and/or breast-cancer-derived mammospheres.

\section{Does breast cancer arise from stem cells or from transit amplifying cells?}

For most mammalian malignancies, in particular epithelial malignancies, genetic alterations accumulate sequentially [56] until a set sufficient to induce malignant transformation coexists within a single cell $[57,58]$. Stem cell compartments are organised in a hierarchical manner with a small number of infrequently proliferating pluripotent stem cells, of rapidly dividing developmentally committed transit amplifying cells and of post-mitotic terminally differentiated cells [1]. Under normal circumstances any mutation that occurs in a transit amplifying cell is lost from the tissue since these cells do not have the capacity for indefinite self-renewal. It is therefore likely that the majority of mutations responsible for malignancy will arise in tissue stem cells [30] or in their developmental precursors [44]. If a transit amplifying cell sustains a mutation that confers indefinite self-renewal, however, and in particular if this cell already has additional mutations required for malignancy by virtue of descent from a tissue stem cell that contains these mutations, then malignancy can arise from a transit amplifying cell. In fact, since transit amplifying cells are both greater in number and proliferate more frequently than stem cells, this may be a common route to malignancy.
Most myeloid leukaemias are thought to arise directly from haematopoietic stem cells. There is evidence, however, that the M3 acute promyelocytic subtype arises from a transit amplifying cell that has acquired the capacity for self-renewal as a consequence of expression of the PML/RAR $\alpha$ fusion protein [5]. When transduced with a leukaemogenic MLL fusion gene in vitro both haematopoietic stem cells and committed myeloid progenitors promptly immortalise, and transplantation leads to AML with apparently identical phenotypes in vivo [59]. This demonstrates not only that malignancy can arise from transit amplifying cells, but also that cancer stem cells do not necessarily correspond to tissue stem cells.

Similar studies with mammary epithelium would be most informative, but unfortunately promotors selectively expressed in stem cells and committed progenitors have yet to be identified; in lieu of these, most investigators have employed the MMTV promotor, which is expressed in a diverse array of cell types. Nevertheless, there is preliminary evidence that different oncogenes target different levels of the differentiation hierarchy. Tumours induced by expression of Wnt (and downstream members of this pathway) express markers of both luminal and basal/myoepithelial lineages [60]. This is not seen with other oncogenes such as $\mathrm{Neu}$ and $\mathrm{H}$-Ras, and suggests origin from a pluripotent precursor, presumably a mammary epithelial stem cell. In support of this hypothesis the number of CD24+CD29hi stem cell candidates was increased in MMTV-wnt-1 transgenic mice but not in MMTV-neu mice [19]. The observation that tumours initiated by carcinogen treatment of rats contain both luminal and basal/myoepithelial cells [61] is also consistent with a stem cell origin for these tumours.

There is an additional route via which mutations arising in transit amplifying cells can persist within the tissue and ultimately lead to malignancy. If dedifferentiation of transit amplifying cells to stem cells is a relatively frequent event, then mutations that occur in transit amplifying cells can be 'fixed'. In fact this mechanism may have particular relevance to mammary carcinogenesis since a population of persistent mammary epithelial cells has been identified that derive from differentiated cells produced during pregnancy, that survive the widespread apoptosis concurrent with post-lactational involution, that have the capacity for self-renewal on serial transplantation and that can differentiate to alveolar cells in subsequent pregnancies (see above) [39,40]. These parityinduced mammary epithelial cells are the cell of origin for a substantial proportion of tumours in transgenic mice expressing the unactivated Her2/neu (ErbB2) oncogene under the MMTV promotor [62], although this is not seen with the wnt 1 oncogene.

\section{Interactions between malignant epithelial cells and the stroma}

Although we have focused on genetic alterations in breast epithelial elements, there is increasing evidence that stromal 
cells are not merely innocent bystanders in tumourigenesis $[63,64]$. The breast stroma accounts for $80 \%$ of the breast volume and comprises fibroblasts, adipocytes and endothelial cells. It has been demonstrated that tumour-associated stromal cells promote the development of epithelial malignancy in vitro and in vivo: premalignant mammary epithelial cells adopt a malignant growth pattern when cultured with tumour-derived stromal cells [65] or when transplanted to transplanted to irradiated mammary fat pads [66], but not when cultured in the presence of normal mammary stromal cells or transplanted to nonirradiated fat pads. Administration of the carcinogen NMU to mammary fat pad stromal cells is sufficient to induce tumour formation following repopulation with normal mammary epithelial cells [67].

The persistence of tumour promotion by breast cancerassociated stromal cells following passage in culture [65] suggests hereditable changes, and clonal genetic alterations [68-71] and epigenetic alterations [72] have been described. For an individual tumour the alterations observed in stromal cells differ from those in malignant epithelial cells, arguing against epithelial-mesenchymal transition. A genome-wide loss of the heterozygosity scan in stromal cells from a number of breast tumours revealed hotspots that were more frequently mutated [71]. This indicates that selective pressures operate during the expansion of tumour-associated stromal cells and that alterations do not merely reflect genetic drift. The precise mechanisms mediating tumour promotion remain unclear; candidates include alterations in expression of growth factors and matrix remodelling enzymes, the recruitment of inflammatory cells and the elaboration of viral oncoproteins [63].

\section{Implications for therapy}

Techniques that permit accurate quantification of the proportion of cancer stem cells in a tumour will permit assessment of the efficacy of current treatment modalities and will guide clinical decision-making. Further characterisation of breast cancer stem cells may enable the design of targeted therapeutics that selectively destroy these cells and block their self-renewal.

\section{Quantification of breast cancer stem cells}

The efficacy of chemotherapy regimens, particularly in the neoadjuvant setting, is usually gauged by the proportion of tumour cells killed. This is reflected clinically by a reduction in size of the tumour. Since cancer stem cells represent a small proportion of the cells within breast tumours, a particular treatment modality could in principle kill a large proportion of differentiated cells while leaving tumour stem cells intact. In fact, CD34+CD38- ${ }^{-}$cells isolated from patients with $\mathrm{AML}$ are more resistant to daunorubicin than more differentiated progenitors [73], suggesting that cancer stem cells may have relative resistance to chemotherapy regimens. The ability to accurately quantify the proportion of cancer stem cells within a tissue sample will permit the identification of treatment regimens that efficiently eliminate cancer stem cells. It will also be instructive to determine whether the proportion of stem versus transit amplifying cells in a given tumour has implications for prognosis.

A related issue is bone marrow micrometastasis. Cytokeratinexpressing cells can be detected in the bone marrow of around one-third of patients with breast cancer and are an independent predictor of poor outcome [74,75]. Importantly these cells are also found in lymph-node-negative patients, and it has been proposed that this may account for the relatively high rate of systemic recurrence in this group of patients. Conversely, a substantial proportion of patients with bone marrow micrometastasis do not develop tumour recurrence. Cytokeratin-positive cells within the bone marrow may comprise both cancer stem cells and committed progenitors with limited proliferative potential. This may have prognostic significance with patients that have a larger proportion of breast cancer stem cells more likely to suffer recurrence. The ability to distinguish cancer stem cells from other tumour cells within the bone marrow may also have implications for the selection of adjuvant therapies.

\section{Targeting of breast cancer stem cells}

With the emergence of the cancer stem cell paradigm has come the realisation that, since only a small proportion of tumour cells have the capacity to self-renew and propagate the tumour, it is this small proportion of tumour cells rather than transit amplifying cells or differentiated cells that must be targeted to achieve long-term cure.

\section{Chemotherapy sensitisation}

One approach is to sensitise breast cancer stem cells to existing chemotherapy regimens. Multidrug resistance has for many years been recognised as a hindrance to effective chemotherapy. This is the phenomenon whereby exposure of cancer cells to a cytotoxic compound leads to resistance not only to that compound, but also to a range of structurally unrelated compounds. A wide variety of pathways have been implicated, including decreased topoisomerase II expression, reduced sensitivity to apoptosis via alterations in the expression of $\mathrm{Bcl} 2$ family members and the efflux of chemotherapeutic agents from cancer cells [76]. Several of these mechanisms, in particular resistance to DNA damage and the efflux of toxic compounds, are also advantageous in tissue stem cells, and their activation in malignancy may reflect not only somatic mutation, but also their intrinsic activation in the tissue stem cells from which cancer arises. Moreover, since cancer stem cells are at the top of the differentiation hierarchy, they will cycle less frequently than other tumour cells and therefore have a greater resistance to antimitotics.

Attention has focused on upregulation of cell surface transporters of the ABC family, in particular ABCG2. This was initially identified as a transcript overexpressed in 
multiresistant breast cancer, hence its alternative name of breast cancer resistance protein [77]. It has since been implicated in the efflux of Hoescht dye from a SP of stem cell candidates isolated from mammary epithelial stem cells (see earlier). The finding of ABCG2 expression in relapsed haematological malignancies has stimulated the development of specific inhibitors [78]. Promising inhibitors for another ABC family transporter implicated in multidrug resistance, P-glycoprotein, are also entering clinical trials [79]. In order to achieve long-term remission, cancer stem cells rather than transit amplifying cells must be destroyed; however, there is evidence that cancer stem cells have a greater resistance to chemotherapeutic agents [73]. The co-administration of inhibitors of the ABC family of transporters and other inhibitors of multidrug resistance may selectively sensitise breast cancer stem cells to chemotherapy.

Signalling pathways implicated in the self-renewal of breast cancer stem cells will provide novel therapeutic targets, and this has stimulated attempts to characterise these pathways.

\section{Wnt}

The Wnt signalling pathway is implicated in the regulation of the stem cell number in a number of tissues, and overexpression leads to a range of malignancies [80]. Wnt is a secreted protein with an intracellular effector, $\beta$-catenin [81]. Loss of Wnt inhibitors (such as SFRP1) and increased levels of $\beta$-catenin have been associated with poor prognosis in breast cancer [82,83]. $\beta$-Catenin has been identified as a crucial survival signal for mammary epithelial stem cells [84]. Mammary tumours arising in mice overexpressing components of this pathway contain cells of both basal/ myoepithelial and luminal phenotypes, suggesting an origin from a common precursor [60]. Mammary epithelial cells derived from mice expressing $\Delta \mathrm{N} \beta$ cat, a constitutively active $\beta$-catenin mutant, more efficiently repopulate a cleared mammary fat pad, suggesting more efficient stem cell selfrenewal [85]. With obvious relevance to potential therapies, Gunther and colleagues utilised a doxycycline-inducible wnt- 1 transgene to show that withdrawal of wnt signalling is sufficient to induce regression of primary mammary tumours and pulmonary metastases [86].

\section{Notch}

A second pathway implicated in mammary carcinogenesis is Notch [87]. Mice expressing a constitutively active form of Notch4 [88] but not other Notch homologues [89] have abnormal mammary morphogenesis and develop mammary tumours. A Notch activating peptide increased secondary and tertiary mammosphere formation 10-fold and increased the proportion of cells with multilineage differentiation capacity 100-fold, implying increased mammary stem cell self-renewal [38]. Notch signalling was shown to act on stem cells to promote self-renewal and on progenitors promoting their proliferation. These effects were completely abrogated by the use of a Notch4 blocking antibody [90].
Hedgehog

The Hedgehog pathway has been implicated in a range of malignancies [91,92]. Overexpression of components of this pathway, including Shh, Ptch1 and Gli1, is found in a large majority of human breast cancer specimens but not in adjacent normal epithelium consistent with constitutive activation of this pathway [93]. In mice, Ptc-1 haploinsufficiency leads to abnormal mammary development with ductal dysplasia and hyperplasia by 5 weeks of age [94]. Gli1 heterozygosity results in abnormal mammary development with ductal dysplasia in parous animals [95]. These results must be interpreted with caution, however, as abnormal mammary development in the Ptc-1 and Gli1 heterozygotes is abrogated on transplantation to a cleared wild-type fat pad $[94,95]$, indicating that the phenotype may be expressed in stromal rather than epithelial cells.

\section{Future prospects}

The spectacular success of the tyrosine kinase inhibitor imatinib in chronic myeloid leukaemia provides a prototype for targeted therapeutics. While these therapeutics can induce dramatic tumour regression even in established malignancy, however, they do not in general lead to a cure but rather control the disease with recurrence on cessation. They are also vulnerable to the emergence of resistant clones with prolonged therapy [96]. This most probably reflects genetic instability in established malignancy and a large number of cells that are targets for mutation. These observations raise fundamental questions about our approach to the control of malignancy. The emerging paradigm for multistep carcinogenesis in epithelial malignancy is a long period of clonal evolution in histologically normal tissue [58], for which a substantial proportion of genetic alterations may occur during development [44]. This leads to histological atypia, dysplasia, pre-invasive disease and, finally, malignancy with the capacity for invasion and metastasis.

Nonsurgical treatment strategies for breast cancer are at present reserved for the treatment of established malignancy, but from first principles any stage in the evolution of malignancy can be targeted. In fact, therapies targeting pathways that govern self-renewal of preinvasive disease such as ductal carcinoma in situ, or even mutant stem cells in histologically normal tissue, may be more effective since the mutation rate is lower at this stage, since there is less likely to be coexistent mutations that confer resistance and since there is a smaller number of target cells for the emergence of resistance. Furthermore, metastasis may occur early in the history of breast cancer - frequently before the tumour becomes apparent clinically or on screening. Since it is probable that a large proportion of otherwise healthy women have cells containing these genetic alterations, this approach could only succeed if a large proportion of apparently healthy women are treated - necessitating a paradigm shift in our approach to breast cancer, and to epithelial malignancy in general. 
We can envisage the development of specific inhibitors targeting the self-renewal of mammary epithelial stem cells. Since the mammary epithelium is unimportant cosmetically, such compounds could be administered to ablate the mammary epithelium in women carrying hereditary breast cancer susceptibility genes such as BRCA1/BRCA2. For women not carrying breast cancer susceptibility genes, however, such an approach may be unacceptable, and therefore in the longer term it is desirable to develop methods permitting repopulation with stem cells derived either from tissue stem cells expanded in vitro or differentiated from embryonic stem cells. Transplanted stem cells could be modified to confer a selective advantage over endogenous stem cells, as has been reported for haematopoietic stem cells [97]. Transplanted cells could also be modified to reduce susceptibility to malignancy; for example, transgenic mice with extra copies of the p53 [98] and INK4A [99] tumour suppressor genes have a substantially decreased incidence of malignancy in the absence of apparent adverse consequences. Although repopulation of mammary stem cells remains a rather distant prospect, intraluminal injection of donor spermatocyte stem cells into seminiferous tubules repopulates the testes of sterile mice leading to normal spermatogenesis [100], so there is no reason to suppose that it should not be technically feasible.

\section{Conclusions}

There is substantial evidence that proliferation within the normal mammary epithelium is organised in a hierarchical manner. Repopulation experiments and lineage analysis support the existence of pluripotent mammary epithelial stem cells, and cell surface markers have been identified to facilitate their purification. Similar techniques have been employed to prospectively isolate breast cancer stem cells. Although a substantial amount of work remains in the further purification and characterisation of these cells, there is little doubt that these new discoveries have profound implications for tailoring of current treatment strategies and for the development of the next generation of targeted therapies.

\section{Competing interests}

The authors declare that they have no competing interests.

\section{References}

1. Potten CS, Loeffler M: Stem cells: attributes, cycles, spirals, pitfalls and uncertainties. Lessons for and from the crypt. Development 1990, 110:1001-1020.

2. Osawa $M$, Hanada $K$, Hamada $H$, Nakauchi H: Long-term lymphohematopoietic reconstitution by a single CD34 low/negative hematopoietic stem cell. Science 1996, 273:242-245.

3. Marshman E, Booth C, Potten CS: The intestinal epithelial stem cell. Bioessays 2002, 24:91-98.

4. Janes SM, Lowell S, Hutter C: Epidermal stem cells. J Pathol 2002, 197:479-491.

5. Passegue E, Jamieson CH, Ailles LE, Weissman IL: Normal and leukemic hematopoiesis: are leukemias a stem cell disorder or a reacquisition of stem cell characteristics? Proc Natl Acad Sci USA 2003, 100:11842-11849.

6. Reya T, Morrison SJ, Clarke MF, Weissman IL: Stem cells, cancer, and cancer stem cells. Nature 2001, 414:105-111.
7. Al-Hajj M, Wicha MS, Benito-Hernandez A, Morrison SJ, Clarke MF: Prospective identification of tumorigenic breast cancer cells. Proc Natl Acad Sci USA 2003, 100:3983-3988.

8. Singh SK, Clarke ID, Terasaki M, Bonn VE, Hawkins C, Squire J, Dirks PB: Identification of a cancer stem cell in human brain tumours. Cancer Res 2003, 63:5821-5828.

9. Hennighausen L, Robinson GW: Signaling pathways in mammary gland development. Dev Cel/ 2001, 1:467-475.

10. Sternlicht MD: Key stages in mammary gland development: the cues that regulate ductal branching morphogenesis. Breast Cancer Res 2006, 8:201.

11. Silberstein GB: Tumour-stromal interactions. Role of the stroma in mammary development. Breast Cancer Res 2001, 3: 218-223.

12. DeOme KB, Faulkin LJ Jr, Bern HA, Blair PB: Development of mammary tumors from hyperplastic alveolar nodules transplanted into gland-free mammary fat pads of female $\mathrm{C} 3 \mathrm{H}$ mice. Cancer Res 1959, 19:515-520.

13. Hoshino K, Gardner WU: Transplantability and life span of mammary gland during serial transplantation in mice. Nature 1967, 213:193-194.

14. Kordon EC, Smith GH: An entire functional mammary gland may comprise the progeny from a single cell. Development 1998, 125:1921-1930.

15. Smith GH: Experimental mammary epithelial morphogenesis in an in vivo model: evidence for distinct cellular progenitors of the ductal and lobular phenotype. Breast Cancer Res Treat 1996, 39:21-31.

16. Chepko G, Smith GH: Three division-competent, structurally distinct cell populations contribute to murine mammary epithelial renewal. Tissue Cell 1997, 29:239-253.

17. Spangrude GJ, Heimfeld S, Weissman IL: Purification and characterization of mouse hematopoietic stem cells. Science 1988, 241:58-62.

18. Stingl J, Eirew P, Ricketson I, Shackleton M, Vaillant F, Choi D, Li $\mathrm{HI}$, Eaves CJ: Purification and unique properties of mammary epithelial stem cells. Nature 2006, 439:993-997.

19. Shackleton M, Vaillant F, Simpson KJ, Stingl J, Smyth GK, AsselinLabat ML, Wu L, Lindeman GJ, Visvader JE: Generation of a functional mammary gland from a single stem cell. Nature 2006, 439:84-88.

20. Sleeman KE, Kendrick H, Ashworth A, Isacke CM, Smalley MJ: CD24 staining of mouse mammary gland cells defines luminal epithelial, myoepithelial/basal and non-epithelial cells. Breast Cancer Res 2006, 8:R7.

21. Welm BE, Tepera SB, Venezia T, Graubert TA, Rosen JM, Goodell MA: Sca-1+ cells in the mouse mammary gland represent an enriched progenitor cell population. Dev Biol 2002 , 245:42-56.

22. Stingl J, Eaves CJ, Kuusk U, Emerman JT: Phenotypic and functional characterization in vitro of a multipotent epithelial cell present in the normal adult human breast. Differentiation 1998, 63:201-213.

23. Stingl J, Eaves CJ, Zandieh I, Emerman JT: Characterization of bipotent mammary epithelial progenitor cells in normal adult human breast tissue. Breast Cancer Res Treat 2001, 67:93-109.

24. Clayton H, Titley I, Vivanco M: Growth and differentiation of progenitor/stem cells derived from the human mammary gland. Exp Cell Res 2004, 297:444-460.

25. Potten CS, Owen G, Booth D: Intestinal stem cells protect their genome by selective segregation of template DNA strands. J Cell Sci 2002, 115:2381-2388.

26. Smith GH: Label-retaining epithelial cells in mouse mammary gland divide symmetrically and retain their template DNA strands. Development 2005, 132:681-687.

27. Cheshier SH, Morrison SJ, Liao X, Weissman IL: In vivo proliferation and cell cycle kinetics of long-term self-renewing hematopoietic stem cells. Proc Natl Acad Sci USA 1999, 96: 3120-3125.

28. Morris RJ, Potten CS: Highly persistent label-retaining cells in the hair follicles of mice and their fate following induction of anagen. J Invest Dermatol 1999, 112:470-475.

29. Braun KM, Niemann C, Jensen UB, Sundberg JP, Silva-Vargas V, Watt FM: Manipulation of stem cell proliferation and lineage commitment: visualisation of label-retaining cells in wholemounts of mouse epidermis. Development 2003, 130:52415255. 
30. Cairns J: Mutation selection and the natural history of cancer. Nature 1975, 255:197-200.

31. Zeps N, Dawkins HJ, Papadimitriou JM, Redmond SL, Walters MI: Detection of a population of long-lived cells in mammary epithelium of the mouse. Cell Tissue Res 1996, 286:525-536.

32. Zeps N, Bentel JM, Papadimitriou JM, D'Antuono MF, Dawkins HJ: Estrogen receptor-negative epithelial cells in mouse mammary gland development and growth. Differentiation 1998, 62:221-226.

33. Clarke RB, Spence K, Anderson E, Howell A, Okano H, Potten CS: A putative human breast stem cell population is enriched for steroid receptor-positive cells. Dev Biol 2005, 277:443-456.

34. Goodell MA, Brose K, Paradis G, Conner AS, Mulligan RC: Isolation and functional properties of murine hematopoietic stem cells that are replicating in vivo. J Exp Med 1996, 183:1797-1806.

35. Alvi AJ, Clayton H, Joshi C, Enver T, Ashworth A, Vivanco MM, Dale TC, Smalley MJ: Functional and molecular characterisation of mammary side population cells. Breast Cancer Res 2003, 5:R1-R8.

36. Jonker JW, Freeman J, Bolscher E, Musters S, Alvi AJ, Titley I, Schinkel AH, Dale TC: Contribution of the ABC transporters Bcrp1 and Mdr1a/1b to the side population phenotype in mammary gland and bone marrow of mice. Stem Cells 2005, 23:1059-1065.

37. Jonker JW, Merino G, Musters S, van Herwaarden AE, Bolscher E, Wagenaar E, Mesman E, Dale TC, Schinkel AH: The breast cancer resistance protein BCRP (ABCG2) concentrates drugs and carcinogenic xenotoxins into milk. Nat Med 2005, 11:127129.

38. Dontu G, Abdallah WM, Foley JM, Jackson KW, Clarke MF, Kawamura MJ, Wicha MS: In vitro propagation and transcriptional profiling of human mammary stem/progenitor cells. Genes Dev 2003, 17:1253-1270.

39. Wagner KU, Boulanger CA, Henry MD, Sgagias M, Hennighausen $\mathrm{L}$, Smith $\mathrm{GH}$ : An adjunct mammary epithelial cell population in parous females: its role in functional adaptation and tissue renewal. Development 2002, 129:1377-1386.

40. Boulanger CA, Wagner KU, Smith GH: Parity-induced mouse mammary epithelial cells are pluripotent, self-renewing and sensitive to TGF-beta1 expression. Oncogene 2005, 24:552560.

41. Tsai YC, Lu Y, Nichols PW, Zlotnikov G, Jones PA, Smith HS: Contiguous patches of normal human mammary epithelium derived from a single stem cell: implications for breast carcinogenesis. Cancer Res 1996, 56:402-404.

42. Deng G, Lu Y, Zlotnikov G, Thor AD, Smith HS: Loss of heterozygosity in normal tissue adjacent to breast carcinomas. Science 1996, 274:2057-2059.

43. Novelli M, Cossu A, Oukrif D, Quaglia A, Lakhani S, Poulsom R, Sasieni $\mathrm{P}$, Carta $\mathrm{P}$, Contini M, Pasca $\mathrm{A}$, et al:: X-inactivation patch size in human female tissue confounds the assessment of tumor clonality. Proc Natl Acad Sci USA 2003, 100:33113314.

44. Frank SA, Nowak MA: Cell biology: developmental predisposition to cancer. Nature 2003, 422:494.

45. Gudjonsson T, Villadsen R, Nielsen HL, Ronnov-Jessen L, Bissell MJ, Petersen OW: Isolation, immortalization, and characterization of a human breast epithelial cell line with stem cell properties. Genes Dev 2002, 16:693-706.

46. Reynolds BA, Weiss S: Clonal and population analyses demonstrate that an EGF-responsive mammalian embryonic CNS precursor is a stem cell. Dev Biol 1996, 175:1-13.

47. Jordan VC, Morrow M: Tamoxifen, raloxifene, and the prevention of breast cancer. Endocr Rev 1999, 20:253-278.

48. Russo J, Ao X, Grill C, Russo IH: Pattern of distribution of cells positive for estrogen receptor alpha and progesterone receptor in relation to proliferating cells in the mammary gland. Breast Cancer Res Treat 1999, 53:217-227.

49. Clarke RB, Howell A, Potten CS, Anderson E: Dissociation between steroid receptor expression and cell proliferation in the human breast. Cancer Res 1997, 57:4987-4991.

50. Smith GH, Medina D: A morphologically distinct candidate for an epithelial stem cell in mouse mammary gland. J Cell Sci 1988, 90:173-183

51. Bonnet D, Dick JE: Human acute myeloid leukemia is organized as a hierarchy that originates from a primitive hematopoietic cell. Nat Med 1997, 3:730-737.
52. Ponti D, Costa A, Zaffaroni N, Pratesi G, Petrangolini G, Coradini $D$, Pilotti S, Pierotti MA, Daidone MG: Isolation and in vitro propagation of tumorigenic breast cancer cells with stem/ progenitor cell properties. Cancer Res 2005, 65:5506-5511.

53. Wulf GG, Wang RY, Kuehnle I, Weidner D, Marini F, Brenner MK Andreeff M, Goodell MA: A leukemic stem cell with intrinsic drug efflux capacity in acute myeloid leukemia. Blood 2001 98:1166-1173.

54. Hirschmann-Jax C, Foster AE, Wulf GG, Nuchtern JG, Jax TW, Gobel U, Goodell MA, Brenner MK: A distinct 'side population' of cells with high drug efflux capacity in human tumor cells. Proc Natl Acad Sci USA 2004, 101:14228-14233.

55. Patrawala L, Calhoun T, Schneider-Broussard R, Zhou J, Claypool $\mathrm{K}$, Tang DG: Side population is enriched in tumorigenic, stemlike cancer cells, whereas ABCG2+ and ABCG2- cancer cells are similarly tumorigenic. Cancer Res 2005, 65:6207-6219.

56. Fearon ER, Vogelstein B: A genetic model for colorectal tumorigenesis. Cell 1990, 61:759-767.

57. Armitage $P$, Doll R: The age distribution of cancer and multistage theory of carcinogenesis. Br J Cancer 1954, 1:1-12.

58. Calabrese P, Tavare S, Shibata D: Pretumor progression: clonal evolution of human stem cell populations. Am J Pathol 2004, 164:1337-1346.

59. Cozzio A, Passegue E, Ayton PM, Karsunky H, Cleary ML, Weissman IL: Similar MLL-associated leukemias arising from selfrenewing stem cells and short-lived myeloid progenitors. Genes Dev 2003, 17:3029-3035.

60. Li Y, Welm B, Podsypanina K, Huang S, Chamorro M, Zhang X Rowlands T, Egeblad M, Cowin P, Werb Z, et al:: Evidence that transgenes encoding components of the Wnt signaling pathway preferentially induce mammary cancers from progenitor cells. Proc Natl Acad Sci USA 2003, 100:15853-15858.

61. Dulbecco R, Armstrong B, Allen WR, Bowman M: Distribution of developmental markers in rat mammary tumors induced by $N$-nitrosomethylurea. Cancer Res 1986, 46:5144-5152.

62. Henry MD, Triplett AA, Oh KB, Smith GH, Wagner KU: Parityinduced mammary epithelial cells facilitate tumorigenesis in MMTV-neu transgenic mice. Oncogene 2004, 23:6980-6985.

63. Tlsty TD, Hein PW: Know thy neighbor: stromal cells can contribute oncogenic signals. Curr Opin Genet Dev 2001, 11:54 59.

64. Shekhar MP, Pauley R, Heppner G: Host microenvironment in breast cancer development: extracellular matrix-stromal cell contribution to neoplastic phenotype of epithelial cells in the breast. Breast Cancer Res 2003, 5:130-135.

65. Shekhar PVM, Werdell J, Santner S, Pauley RJ, Tait, L: Breast stroma plays a dominant regulatory role in breast epithelial growth and differentiation: implications for tumor development and progression. Cancer Res 2001, 61:1320-1326.

66. Barcellos-Hoff $\mathrm{MH}$, Ravani SA: Irradiated mammary gland stroma promotes the expression of tumorigenic potential by unirradiated epithelial cells. Cancer Res 2000, 60:1254-1260.

67. Maffini MV, Soto AM, Calabro JM, Ucci AA, Sonnenschein C: The stroma as a crucial target in rat mammary gland carcinogenesis. J Cell Sci 2004, 117:1495-1502.

68. Moinfar F, Man YG, Arnould L, Bratthauer GL, Ratschek M, Tavassoli FA: Concurrent and independent genetic alterations in the stromal and epithelial cells of mammary carcinoma: implications for tumorigenesis. Cancer Res 2000, 60:2562-2566.

69. Kurose K, Hoshaw-Woodard S, Adeyinka A, Lemeshow S, Watson $\mathrm{PH}$, Eng C: Genetic model of multi-step breast carcinogenesis involving the epithelium and stroma: clues to tumour-microenvironment interactions. Hum Mol Genet 2001, 10:1907-1913.

70. Kurose K, Gilley K, Matsumoto S, Watson PH, Zhou XP, Eng C: Frequent somatic mutations in PTEN and TP53 are mutually exclusive in the stroma of breast carcinomas. Nat Genet 2002, 32:355-357

71. Fukino K, Shen L, Matsumoto S, Morrison CD, Mutter GL, Eng C: Combined total genome loss of heterozygosity scan of breast cancer stroma and epithelium reveals multiplicity of stromal targets. Cancer Res 2004, 64:7231-7236.

72. Hu M, Yao J, Cai L, Bachman KE, van den Brule F, Velculescu V, Polyak K: Distinct epigenetic changes in the stromal cells of breast cancers. Nat Genet 2005, 37:899-905.

73. Costello RT, Mallet F, Gaugler B, Sainty D, Arnoulet C, Gastaut $\mathrm{JA}$, Olive D: Human acute myeloid leukemia CD34+/CD38- 
progenitor cells have decreased sensitivity to chemotherapy and Fas-induced apoptosis, reduced immunogenicity, and impaired dendritic cell transformation capacities. Cancer Res 2000, 60:4403-4411.

74. Ozbas S, Dafydd H, Purushotham AD: Bone marrow micrometastasis in breast cancer. Br J Surg 2003, 90:290-301.

75. Braun S, Vogl FD, Naume B, Janni W, Osborne MP, Coombes RC, Schlimok G, Diel IJ, Gerber B, Gebauer G, et al.: A pooled analysis of bone marrow micrometastasis in breast cancer. N Engl J Med 2005, 353:793-802.

76. Norgaard JM, Olesen LH, Hokland P: Changing picture of cellular drug resistance in human leukemia. Crit Rev Oncol Hematol 2004, 50:39-49.

77. Doyle LA, Yang W, Abruzzo LV, Krogmann T, Gao Y, Rishi AK, Ross DD: A multidrug resistance transporter from human MCF-7 breast cancer cells. Proc Natl Acad Sci USA 1998, 95: 15665-15670.

78. Sugimoto $\mathrm{Y}$, Tsukahara S, Ishikawa $E$, Mitsuhashi J: Breast cancer resistance protein: molecular target for anticancer drug resistance and pharmacokinetics/pharmacodynamics. Cancer Sci 2005, 96:457-465.

79. Thomas $\mathrm{H}$, Coley $\mathrm{HM}$ : Overcoming multidrug resistance in cancer: an update on the clinical strategy of inhibiting p-glycoprotein. Cancer Control 2003, 10:159-165.

80. Polakis P: Wnt signaling and cancer. Genes Dev 2000, 14: 1837-1851.

81. Moon RT, Bowerman B, Boutros M, Perrimon N: The promise and perils of Wnt signaling through beta-catenin. Science 2002, 296:1644-1646.

82. Klopocki E, Kristiansen G, Wild PJ, Klaman I, Castanos-Velez E, Singer G, Stohr R, Simon R, Sauter G, Leibiger H, et al.: Loss of SFRP1 is associated with breast cancer progression and poor prognosis in early stage tumours. Int $J$ Oncol 2004, 25:641-649.

83. Ugolini F, Charafe-Jauffret E, Bardou VJ, Geneix J, Adelaide J, Labat-Moleur F, Penault-Llorca F, Longy M, Jacquemier J, Birnbaum $\mathrm{D}$, et al:: WNT pathway and mammary carcinogenesis: loss of expression of candidate tumour suppressor gene SFRP1 in most invasive carcinomas except of the medullary type. Oncogene 2001, 20:5810-5817.

84. Tepera SB, McCrea PD, Rosen JM: A beta-catenin survival signal is required for normal lobular development in the mammary gland. J Cell Sci 2003, 116:1137-1149.

85. Liu BY, McDermott SP, Khwaja SS, Alexander CM: The transforming activity of Wnt effectors correlates with their ability to induce the accumulation of mammary progenitor cells. Proc Natl Acad Sci USA 2004, 101:4158-4163.

86. Gunther EJ, Moody SE, Belka GK, Hahn KT, Innocent N, Dugan $\mathrm{KD}$, Cardiff RD, Chodosh LA: Impact of p53 loss on reversal and recurrence of conditional Wnt-induced tumorigenesis. Genes Dev 2003, 17:488-501.

87. Brennan $\mathrm{K}$, Brown AMC: Is there a role for Notch signalling in human breast cancer? Breast Cancer Res 2003, 5:69-75.

88. Soriano JV, Uyttendaele H, Kitajewski J, Montesano R: Expression of an activated Notch4(int-3) oncoprotein disrupts morphogenesis and induces an invasive phenotype in mammary epithelial cells in vitro. Int J Cancer 2000, 86:652-659.

89. Behbod F, Rosen JM: Will cancer stem cells provide new therapeutic targets? Carcinogenesis 2005, 26:703-711.

90. Dontu G, Jackson KW, McNicholas E, Kawamura MJ, Abdallah WM, Wicha MS: Role of Notch signaling in cell-fate determination of human mammary stem/progenitor cells. Breast Cancer Res 2004, 6:R605-R615.

91. Magliano MP, Hebrok M: Hedgehog signaling in cancer formation and maintenance. Nat Rev Cancer 2003, 3:903-911.

92. Berman DM, Karhadkar SS, Maitra A, Montes De Oca R, Gerstenblith MR, Briggs K, Parker AR, Shimada Y, Eshleman JR, Watkins DN, et al.: Widespread requirement for Hedgehog ligand stimulation in growth of digestive tract tumours. Nature 2003, 425: 846-851.

93. Kubo $M$, Nakamura $M$, Tasaki A, Yamanaka $N$, Nakashima $H$, Nomura M, Kuroki S, Katano M: Hedgehog signaling pathway is a new therapeutic target for patients with breast cancer. Cancer Res 2004, 64:6071-6074.

94. Lewis MT, Ross S, Strickland PA, Sugnet CW, Jimenez E, Scott MP, Daniel CW: Defects in mouse mammary gland development caused by conditional haploinsufficiency of Patched-1. Development 1999, 126:5181-5193.
95. Hui C, Daniel CW: The Gli2 transcription factor is required for normal mouse mammary gland development. Dev Biol 2001, 238:133-144.

96. Klein S, McCormick F, Levitzki A: Killing time for cancer cells. Nat Rev Cancer 2005, 5:573-580.

97. Milsom MD, Woolford LB, Margison GP, Humphries RK, Fairbairn $\mathrm{LJ}$ : Enhanced in vivo selection of bone marrow cells by retroviral-mediated coexpression of mutant 06-methylguanineDNA-methyltransferase and HOXB4. Mol Ther 2004 10:862-873.

98. Garcia-Cao I, Garcia-Cao M, Martin-Caballero J, Criado LM, Klatt P, Flores JM, Weill JC, Blasco MA, Serrano M: 'Super p53' mice exhibit enhanced DNA damage response, are tumor resistant and age normally. EMBO J 2002, 21:6225-6235.

99. Matheu A, Pantoja C, Efeyan A, Criado LM, Martin-Caballero J, Flores JM, Klatt P, Serrano M: Increased gene dosage of Ink4a/ Arf results in cancer resistance and normal aging. Genes Dev 2004, 18:2736-2746.

100. Brinster RL, Zimmermann JW: Spermatogenesis following male germ-cell transplantation. Proc Natl Acad Sci USA 1994, 91: 11298-11302. 